and that it is highly probable that, according to the theory of M. Beau, of Paris,* these sounds either owe their existence to, or are, in fact, produced or modified, by the transmission or reverberation of a sound which takes place in the superior respiratory passages, and which has been termed the "guttural" respiratory sound. It was stated that great similarity existed between this sound and that produced by a pair of bellows, when blown, and that this was admitted by Laennec; it was also noticed that a similar sound could be produced by blowing air through almost any tube, differing in tone and intensity, according to the diameter or shape of the aperture, the foree with which the air is made to issue from it, or the nature of the materials of which it is composed.

In support of the first theory it was observed, that the best experiment was that of Magendie, in which air was blown into the lungs by means of a pair of bellows, and in which sounds, resembling the respiratory murmurs, were perceived, and from which MI. Masendie drew the conclusion, that because air passed to and from the lungs during this experiment, as well as during respiration, accompanied by a sound similar to the murmur of respiration, therefore the respiratory sounds are produced by the fric. tion of the air against the parietes of the air tubes and cells through which it passes.

The experiments of M. Beau, in support of his particular theory, it was noticed, were very open to objections, and did not bear out very clearly the conclusions at which he arrives, thus accounting, perhaps, for the neglect which his particular view of the subject has met with. For the purpose of obviating these, and showing in a more distinct manner, if possible, the probable truth of this theory. to a certain extent at least, several experiments apparently calculated to prove this in a less objectionable manner, were devised.

In the experiments performed to test the theory of M. Beau, no stream of air was allowed to pass through those parts, the subject of observation, which were only allowed to become, and 1 emain distended with air, while at the same time the sound produced by the issuing of the air from an air.condensing apparatus, or from the mouth, and which very nearly resembles that produced by the bellows, which, as before stated, is similar to the guttural sound, was found to have passed freely, in one experiment, throughout an artery eighteen inches in length, and to be perceived very nearly, if not quite, as lond in this as in another artery connected with it, and through which a current of air passed. In another experiment, in which the lungs of a lamb were nsed, sounds analogous to the tracheal,

* Archires Generales, 1831. onchial, and vesicular respiratory mur murs, were distinctly perceived, although no current of ail passed along the air tubes, $r^{\circ}$ cells; and in the case of a bladder attached to one of the great bifurcations of the trachea, a sound louder than that in the bronchial tube was perceived, when the former was contracted to about an inch and a half, or two inches,-feebler when larger, and assuming, as its size was increased, a gentle, shrill, ringing, amphoric character. In these different observations no current of air passed along the parts the subjects of examination, but was conveyed away in a manner which it is unnecessary here to describe.

These experiments were not advanced to prove that the guttural sound, or that which takes place in the superior respiratory passages, is the only source of the sounds perceived during respiration, but 10 show that in all probability it exeris a considerable influence, if not in producing, at least in modifying, the different respiratory sounds known as the vesicular, bronchial, tracheal, cavernous, and amphoric respiratory mu:murs, all of which have hitherto been $e_{\varepsilon}$ plained according to the views of Laennes.

\section{BEETLES IN THE MOUTH.}

\section{To the Editor of The Lancer.}

Sin :- Having only just received the number's of your invaluable periodical for the last month, I hasten to reply to the communication of an anonymous correspondent concerning a case of mine. Had it not been for the prejudicial influence such errors might have acquired through the medium of The Lancet, if unnoticed, I should have treated the writer with the silence he deserves. But as I believe the feeling which induced him to fabricate such statements is evident to all who havo read them, I shall confine my remar's to that portion which is interesting to the profession, confident that truth is a sufficiently powerful antidote to neutralise any thing he may have invented.

The extract from the "Lincoln Gazette" is full of erroneous statements, and it was on ac. count of them, and the additions it received from the editur of the "Stamford Mercury," that I addressed to him a short explanation of the fact which others consider so remarkable. Your correspondent has omitted the first seven and last two lines of my letter; the latter I will supply for him. "The case is thoroughly known here," \&ce.

This, I fear has excited his envy. The six following lines are correct, the rest are invented by $M r$. Anonymous.

I will now state the case, and afterwards endeavour to answer the queries which close the letter. 
James Boyears, wt.67, horse dealer, seven meeting, as published in the "Globe" of years ago injured his neck by striking his head against the lintel of a stable-door, when on horseback; ever since which period he has been partially paralysed, and has declined gradually during the past winter, being compelled to keep his bed. On March 18th Jast, he requested me to examine his mouth, which he described as being very painful. I found the left canine tooth of the lower jaw denuded to the bottom of its socket (the external lamina of bone forming the socket being deficient,) the gums on each side, and below the tooth, up to the lower lip ulcerated deeply. I did not remove the touth, but directed lint saturated with lotio calcis chlor, to be constantly applied. I visited hin two or three times a week, and observed the ulcer proceed but slowly, causing little pain.

On April 29th, he informed me that he had suffered severely during the last two days, and could scarcely bear the smell that proceeded from his mouth. Having depressed the lip, I saw the ulcer had increased in size, and in one part had advanced so deep$1 y$, as to penetrate the skin under the lower lip. The tooth had fallen out of its socket, which was occupied by what at first appear$e d$ to be a brown stump (his teeth being of that colour); thinking this might cause irritation, I removed it with the forceps, and then the nurse saw as well as myself, that it was a dead beetle. Having met with such an unexpected intruder I searched further, and found an ovum occupying the siluation of the next bicuspid tooth, a stump of which had fallen out, and was lying with another ovum at the bottom of the ulcer. After this period, to the patient's death, which occurred on May 9 th, he expressed himself much relieved, and testified to many of the facts here asserted. I took the beetle, \&c., home, and preserved them in alcohol. Many individuals, both professional and otherwise have seen them, and are satisfied. If the gentleman who bas given so nuch credit to rumour shonld not live too far from me, aud would favour me with a call, I will show them to him.

If the above be not sufficient answers to the queries of your correspondent, I will state them more clearly.

1. An ulcer in the gums and inside of the lip, must be inside the mouth.

2. The bottom of an ulcer is the lowest part thereof.

3. The sockets of teeth continue to exist even in old age, as in this instance, for two or three days after the teeth have fallen out.

4. The instrument used was the forceps.

Having answered these questions seriatim, and as seriously as their importance demands, I would only add, that the attention of the Entomological Society was called to the case by the Rev. F. W. Hope, on Monday June 4 , and from the report of that June 6 , it appears, that " this complaint, known by the name of the beetle disease, is very rare, but in this instance is analogous with the pickle cases in Ireland and Sweden. As with parasites in dogs and other animals, these insects only attack those persons in whom from very great prostration of strength there is predisposition to decay." I am, Sir, your obedient servant,

Barton-upon-Humber, JOHN MORLey. August 1838.

\section{MORISON'S PILLS.}

THE following is an additional example of the benefits conferred upon mankind by the Hygeian philanthropist. Had we lived in the good old times when a man was compelled " to do unto himself as he had done unto others," the Hygeist would have been forced to swallow a peck of his own pills, and thus relieve society of his presence. Now-a-days, however, when the poisoning of a few humble individuals is altogether thrown into the shade by the wholsale effects of "dietaries and water gruel," the career of Morison will not be checked until a few persons of note shall have fallen victims to his cupidity. In the interests of the poor and unprotected, we fervently say,adceniat cito dies.

\section{DEATH ACCELERATED BY MORISON'S PILLS.}

(From the Nottingham Reniew.)

On Wednesday an inquest was held at the house of Mr. George Brewster, the sign of the Shakspeare Cottage, at New Lenton, to inquire into the death of Anthony Ibbotson, formerly a well-known exciseman of that place.

Mary, wife of the said George Brewster, deposed that deceased lised next door to her, was a pensioner, about 64 years of age, and during the last three weeks had lived quite alone in his house. About 11 o'clock on Monday morning last, she went into his house, and saw him sitting in a chair, looking dreadfully ill; asked him how long he had been ill; he replied, since 10 o'clock. Made him some gruel, and attended to other matters for his comfort. By his desire left him alone, as he said he would knock for her when he wanted ber. Saw him again that night, at 8 o'clock, when he complained of great pain in the lower part of his bowels. On Tuesday morning, about 7 o'clock, he got up and came down stairs, but be said he was very bad. Made him some broth of a rabbit received from his daughter, which he drank; he then appeared vely bad, and smoked his pipe; he afterwards vomited as much as two quarts of green fluid, and then 